N Engl J Med. 2013 October 17; 369(16): 1537-1543. doi:10.1056/NEJMcp1210380.

\title{
clinical practice:
}

Calcium Supplements and Fracture Prevention

\author{
Douglas C. Bauer, M.D. \\ Departments of Medicine and Epidemiology and Biostatistics, University of California, San \\ Francisco, San Francisco
}

\begin{abstract}
This Journal feature begins with a case vignette highlighting a common clinical problem. Evidence supporting various strategies is then presented, followed by a review of formal guidelines, when they exist. The article ends with the author's clinical recommendations.

A 62-year-old healthy woman presents for routine care. She has no history of fracture, but she is worried about osteoporosis because her mother had a hip fracture at 72 years of age. She exercises regularly and has taken over-the-counter calcium carbonate at a dose of $1000 \mathrm{mg}$ three times a day since her menopause at 54 years of age. This regimen provides $1200 \mathrm{mg}$ of elemental calcium per day. She eats a healthy diet with multiple servings of fruits and vegetables and consumes one 8-oz serving of low-fat yogurt and one glass of low-fat milk almost every day. She recently heard that calcium supplements could increase her risk of cardiovascular disease and wants your opinion about whether or not she should receive them. What would you advise?
\end{abstract}

\section{The Clinical Problem}

Both clinicians and patients are likely to be confused by the inconsistent and sometimes conflicting advice about the amount of calcium intake required to reduce the risk of fracture and, in particular, whether calcium supplements are necessary. Long-term calcium deficiency can clearly confer a predisposition to osteoporosis, ${ }^{1}$ but many persons mistakenly believe that postmenopausal and age-related bone loss and the associated increase in susceptibility to fracture can largely be avoided with the use of calcium supplementation. Although some persons remain at risk for calcium deficiency, other persons, particularly those receiving calcium supplements, may receive more than the recommended daily intake.

The complex and incompletely understood interaction between calcium and vitamin D intake complicates our understanding of the benefits and risks associated with either one alone. ${ }^{2,3}$ For example, a recent randomized trial showed that even high doses of vitamin $\mathrm{D}_{3}$ (4800 IU per day) had modest beneficial effects on calcium absorption (a $6 \%$ increase) among postmenopausal women with low serum levels of 25 -hydroxyvitamin D. ${ }^{4}$

Copyright () 2013 Massachusetts Medical Society. All rights reserved.

Address reprint requests to, Dr. Bauer at the University of California, San Francisco, 185 Berry St., Suite 5700, San Francisco, CA 94105, or at dbauer@psg.ucsf.edu.

No other potential conflict of interest relevant to this article was reported.

Disclosure forms provided by the author are available with the full text of this article at NEJM.org. 
Furthermore, a number of clinical trials have studied the combination of calcium plus vitamin $\mathrm{D}$ in various doses, but fewer trials have examined the effects of calcium alone on the skeleton.

This review summarizes our current understanding of calcium intake as it relates to fracture risk and discusses concerns about the safety of calcium supplements. Other reviews have addressed the physiology of calcium metabolism and the ongoing controversies about vitamin D. ${ }^{2,5}$

\section{Strategies and Evidence}

Calcium Requirements-More than $98 \%$ of all calcium in the body is contained within the skeleton. Bone serves as a reservoir for calcium, which can be stored and released when needed. Calcium has at least two key physiological functions in adults: it is an intracellular messenger and it is a key component of hydroxyapatite, which is present in great quantities in the organic matrix of bone and provides strength and rigidity to the skeleton. Because of obligate losses in urine, sweat, and stool, insufficient calcium intake over a prolonged period may eventually affect important physiological processes.

Primarily on the basis of studies of calcium balance in persons younger than 50 years of age and the known acceleration of bone loss that occurs with menopause and advanced aging, the Institute of Medicine (IOM) has issued guidelines regarding the dietary intake of calcium according to sex and $\operatorname{age}^{5}$ (Table 1). The recommended calcium intake and the calcium content of various foods and supplements are quantified in milligrams of elemental calcium. Different supplement formulations provide different amounts of elemental calcium. The recommended dietary allowances are based on requirements for healthy populations. The recommended upper intake levels are based primarily on the risk of nephrolithiasis observed in studies of calcium supplementation in postmenopausal women. Calcium absorption is increased in pregnant and lactating women, but the recommended calcium intake for these women does not differ from that for other women in the same age group.

In a population-based study involving adults in the United States, the dietary intake of elemental calcium varied according to age group but averaged 900 to $1200 \mathrm{mg}$ in men and 750 to $850 \mathrm{mg}$ in women; the lowest intake was observed among men and women older than 70 years of age. ${ }^{6}$ More than $70 \%$ of dietary calcium comes from dairy products. ${ }^{5}$ To estimate a person's daily dietary calcium intake, clinicians can assume that most adults consume about $300 \mathrm{mg}$ of calcium per day from nondairy sources (e.g., various vegetables and grains) and then estimate the total daily intake by calculating the additional daily intake of dairy products (Table 2). The use of calcium supplements is common; cross-sectional surveys have shown that $43 \%$ of U.S. adults (and almost $70 \%$ of postmenopausal women) regularly take calcium supplements. ${ }^{8}$ Despite frequent use of calcium supplements, many adults in the United States, particularly postmenopausal women, do not consume the recommended 1000 to $1200 \mathrm{mg}$ of elemental calcium per day, and few consume more than the recommended upper intake level of 2000 to $2500 \mathrm{mg}$ per day.

Dietary Calcium versus Calcium Supplements-In general, calcium-rich foods and beverages, particularly dairy products, are the preferred sources of calcium because they are 
widely available, and with the exception of lactose intolerance, they are associated with few adverse effects. Some evidence suggests that a greater proportion of ingested calcium is absorbed from certain dietary sources such as broccoli and kale than from calcium supplements. ${ }^{5}$ Although data involving clinical outcomes (fractures) are lacking, physiological studies suggest no material differences in the metabolic actions of dietary calcium as compared with calcium obtained from supplements. ${ }^{9,10}$ Therefore, the decision about whether or not to receive supplements depends on the adequacy of dietary calcium intake and the balance between the potential benefits and harms of supplements. The safety and side-effect profile of calcium supplements are described below.

Calcium supplements are available over the counter; labels commonly include both the total milligrams of calcium salt and the milligrams of elemental calcium in each tablet. Determination of the dose required to meet daily calcium requirements is based on the amount of elemental calcium. Commonly used preparations include purified calcium carbonate, calcium citrate, and, to a lesser extent, calcium lactate and calcium gluconate; preparations differ in the amount of elemental calcium provided (Table 3). Calcium carbonate provides relatively high elemental calcium content (40\%) and is inexpensive and widely available. As compared with other calcium supplements, calcium carbonate is more likely to cause constipation and bloating ${ }^{11}$ and should be taken with meals, since gastric acidity is required for sufficient absorption. As compared with calcium carbonate, calcium citrate provides less elemental calcium (21\%), but it is a reasonable alternative in patients with bothersome gastrointestinal symptoms; it may be taken with or without meals, since absorption is not dependent on gastric acidity. If daily supplementation with more than 500 $\mathrm{mg}$ of elemental calcium is required, divided doses are recommended to improve absorption and minimize gastrointestinal side effects.

Potential Benefits of Calcium Intake-Perimenopausal and age-related bone loss, and the accompanying increased risk of fracture, occur when there is a net loss of calcium in the skeleton due to an imbalance between bone resorption and bone formation. Although perimenopausal bone loss is primarily related to the loss of estrogen, age-related bone loss in both men and women is determined by genetic, hormonal, and other factors. Observational studies suggest that bone loss and fracture risk increase when calcium intake is below 700 to $800 \mathrm{mg}$ per day. ${ }^{1,12}$ Conversely, the effect of additional calcium intake on bone loss among persons who do not have a calcium deficiency is less clear and is probably modest. ${ }^{13}$

Many trials have assessed the antifracture benefits of calcium supplements, but most, such as the Women's Health Initiative (WHI) Calcium/Vitamin D Supplementation trial, included vitamin $\mathrm{D}$ as part of the intervention and did not preferentially recruit persons with low dietary calcium intake. ${ }^{14}$ The WHI trial did not show a significant reduction in hip fractures or other fractures in women randomly assigned to $1000 \mathrm{mg}$ of elemental calcium plus 400 IU of vitamin D per day as compared with women assigned to placebo, perhaps because the mean calcium intake in the placebo group was $1154 \mathrm{mg}$ per day. ${ }^{15}$ However, pooled analyses of the combination of calcium plus vitamin D have suggested a modest protective effect on fractures, particularly among frail and elderly persons. ${ }^{16,17}$ For example, a metaanalysis of 16 placebo-controlled trials of calcium and vitamin D supplements (including the WHI trial) recently performed for the U.S. Preventive Services Task Force showed an 
overall $12 \%$ reduction in the risk of any fracture. ${ }^{16}$ In this analysis, the benefits of calcium and vitamin D with respect to fracture risk were significant among institutionalized persons (relative risk, 0.71 ; $95 \%$ confidence interval $[\mathrm{CI}], 0.57$ to 0.89 ) but not among communitydwelling persons (relative risk, $0.89 ; 95 \% \mathrm{CI}, 0.76$ to 1.04$)(\mathrm{P}=0.07$ for interaction). Fewer trials have specifically examined the skeletal effects of calcium supplements alone, but a meta-analysis that pooled the results of 9 randomized trials of calcium supplements alone (involving a total of 6517 persons) showed that the overall reduction in fractures was $10 \% .{ }^{17}$ Conversely, a pooled analysis of 3 trials of calcium alone showed an unexpected $50 \%$ increase in the risk of hip fracture. ${ }^{18}$ Thus, current evidence suggests that supplementation with calcium and vitamin D or with calcium alone has a modest overall effect on the risk of fracture, and whether or not routine use of supplements is beneficial for communitydwelling persons remains uncertain.

Potential Harms of Calcium Intake-Although calcium supplements have few side effects, minor constipation and dyspepsia are common. The risk of nephrolithiasis is increased with the use of calcium supplements (the relative risk was 1.17 in the WHI trial), ${ }^{19}$ and the risk appears to be dose-dependent. ${ }^{20}$ Conversely, in observational studies, a higher dietary intake of calcium has been associated with a lower risk of nephrolithiasis, perhaps because of a reduction in the intestinal absorption of oxylate. ${ }^{21}$ Early studies suggested that the use of calcium supplements might increase the risk of prostate cancer among men, but a recent meta-analysis that included more than 4000 cases of prostate cancer showed no association with the use of calcium supplements. ${ }^{16}$

Several studies have raised concerns about a possible increase in cardiovascular risk associated with calcium supplementation. A meta-analysis of published results of 11 placebo-controlled trials of calcium supplements without vitamin D showed an increased risk of myocardial infarction among persons randomly assigned to calcium (odds ratio, 1.27; $95 \%$ CI, 1.01 to 1.59 ). ${ }^{22}$ The authors speculated that transient supplement-related increases in serum calcium levels ${ }^{18}$ might precipitate arrhythmias or perhaps promote vascular calcification. This meta-analysis received considerable attention but was criticized because of inconsistent adjudication of events, marginal statistical significance, and exclusion of trials assessing calcium plus vitamin D. Among the trials not included in this meta-analysis was the WHI trial, ${ }^{14}$ which involved more than 36,000 women and showed no significant increase in adjudicated cardiovascular events ${ }^{23}$ or overall mortality ${ }^{24}$ among women who received calcium plus vitamin $D$. In a subsequent meta-analysis, the same investigators included data from trials of calcium plus vitamin D, including some of the WHI trial data, ${ }^{25}$ but they still excluded WHI participants who were receiving calcium supplements at baseline (approximately 54\% ${ }^{14,23}$ ); the pooled summary estimate of the risk of myocardial infarction associated with supplementation in this updated analysis yielded similar results (odds ratio, 1.24; $95 \% \mathrm{CI}, 1.07$ to 1.45 ). The exclusion was based on the argument that a risk associated with supplements might be obscured among these women if it was attributable to abrupt changes in plasma calcium concentrations after the consumption of supplements. This approach has been subject to criticism and to considerable debate. ${ }^{26-30}$ A 2010 metaanalysis $^{31}$ that included all participants in the WHI trial showed no significant relationship between supplementation and cardiovascular events in pooled analyses of 2 trials of calcium 
plus vitamin D (relative risk, 1.04; 95\% CI, 0.92 to 1.18 ) or in 3 trials of calcium supplements alone (relative risk, 1.14; $95 \%$ CI, 0.92 to 1.41 ). In another placebo-controlled trial of supplementation with calcium carbonate (1200 mg of elemental calcium per day) involving 1460 older women (mean age, 75 years), ${ }^{32}$ calcium supplementation did not result in an increase in the risk of death or atherosclerotic events requiring hospitalization (identified through a validated registry) over a follow-up period of 5 years.

Observational studies have also yielded conflicting results. ${ }^{33-41}$ For example, whereas two large, prospective cohort studies showed that the use of calcium supplements was associated with an increased risk of cardiovascular events or death, ${ }^{33,34}$ a large Canadian prospective cohort study ${ }^{35}$ and the extended follow-up of the WHI trial ${ }^{36}$ showed no significant association between the use of calcium supplements and cardiovascular events. Several studies have shown no relationship between higher dietary intake of calcium and adverse cardiovascular outcomes. ${ }^{33-35,37-39}$ In contrast, a recent study involving a Swedish cohort showed that, as compared with women with intakes between 600 and $999 \mathrm{mg}$ per day, rates of death from cardiovascular causes and death from any cause were higher among women with a dietary or total calcium intake of $1400 \mathrm{mg}$ per day or more but there was no increased risk with intakes of 1000 to $1399 \mathrm{mg}$ per day. ${ }^{40}$ Neither the prospective Framingham Heart Study ${ }^{41}$ nor the WHI trial ${ }^{42}$ showed a relationship between the use of calcium supplements and the coronary calcium score.

In summary, the evidence suggesting adverse cardiovascular effects of calcium supplementation is inconsistent, and an accepted biologic explanation is lacking; the clinical significance of transient supplement-related increases in serum calcium levels is unknown. However, pending further data, a reasonable approach is to preferentially encourage dietary calcium intake and discourage the routine use of calcium supplements.

Patient Education-Patients who can consume dairy products without adverse effects should be encouraged to regularly consume them along with other foods that have a high calcium content (Table 2). Since calcium fortification of processed food and beverages is variable, labels must be checked carefully to determine the calcium (and caloric) content per serving and the serving size. For persons who are unable to meet recommended daily calcium requirements with dietary intake alone, calcium supplementation should be discussed; the side-effect profile (Table 3) and cost should be considered in choosing a supplement. ${ }^{11}$ Supplement dosing combined with dietary intake should be sufficient to approximate but not exceed the IOM daily guidelines.

\section{Areas of Uncertainty}

Further research is needed to determine whether clinically important differences exist between formulations of calcium supplements with respect to skeletal benefits and potential side effects and to establish calcium requirements for premenopausal women, men, and nonwhite populations. ${ }^{43}$ In addition, data from randomized trials that include systematic collection and adjudication of cardiovascular events are needed to clarify whether calcium supplementation increases cardiovascular risk. 


\section{Guidelines}

The IOM has issued guidelines for daily dietary calcium intake in children and adults (Table 1).

An expert panel convened in 2011 by the American Society for Bone and Mineral Research found that the evidence was insufficient to conclude that calcium supplements cause cardiovascular events. ${ }^{44}$

In a 2013 update, ${ }^{45}$ the U.S. Preventive Services Task Force found insufficient evidence to assess the benefits and harms of daily supplementation with more than $1000 \mathrm{mg}$ of calcium (or more than $400 \mathrm{IU}$ of vitamin D) for the primary prevention of fractures in noninstitutionalized postmenopausal women. However, the task force cited the negative results of the WHI trial and recommended against routine daily supplementation with 1000 $\mathrm{mg}$ or less of calcium or $400 \mathrm{IU}$ or less of vitamin D. They found insufficient evidence to recommend for or against the use of calcium supplements in men and premenopausal women. Although the authors of the recommendation statement acknowledged the importance of adequate calcium intake for skeletal health, they did not address supplementation specifically in persons with inadequate dietary intake.

\section{Conclusions and Recommendations}

The healthy postmenopausal woman described in the vignette reports a current total daily intake of $2240 \mathrm{mg}$ of elemental calcium: a dietary intake of about $1040 \mathrm{mg}$ (approximately $300 \mathrm{mg}$ from nondairy sources and $740 \mathrm{mg}$ from dairy products) and supplements that provide $1200 \mathrm{mg}$ of calcium. Since her calcium intake is substantially greater than the IOM recommendation of $1200 \mathrm{mg}$ per day for postmenopausal women, I would recommend that she increase her dietary calcium intake by $200 \mathrm{mg}$ per day and discontinue her calcium supplements. If increasing her dietary intake is not feasible, she can reduce her calcium carbonate supplementation to one 500-mg tablet each day. She should be informed that supplement use, but not increased dietary intake, modestly increases the risk of nephrolithiasis, and she should be advised about a potential increased risk of cardiovascular events, although the evidence of the latter is currently inconsistent and inconclusive. If she continues to supplement her dietary calcium intake, she should be advised to take calcium carbonate with meals to optimize absorption.

\section{Acknowledgments}

Dr. Bauer reports receiving grant support through his institution from Amgen and Novartis.

\section{References}

1. Dawson-Hughes B. Calcium insufficiency and fracture risk. Osteoporos Int. 1996; 6(Suppl 3):3741. [PubMed: 8931045]

2. Rosen CJ. Vitamin D insufficiency. N Engl J Med. 2011; 364:248-254. [PubMed: 21247315]

3. Hunt CD, Johnson LK. Calcium requirements: new estimations for men and women by crosssectional statistical analyses of calcium balance data from metabolic studies. Am J Clin Nutr. 2007; 86:1054-1063. [PubMed: 17921384] 
4. Gallagher JC, Yalamanchili V, Smith LM. The effect of vitamin D on calcium absorption in older women. J Clin Endocrinol Metab. 2012; 97:3550-3556. [PubMed: 22855333]

5. Institute of Medicine. Dietary reference intakes for calcium and vitamin D. Washington, DC: National Academies Press; 2011.

6. Bailey RL, Dodd KW, Goldman JA, et al. Estimation of total usual calcium and vitamin D intakes in the United States. J Nutr. 2010; 140:817-822. [PubMed: 20181782]

7. Beltsville, MD: U.S. Department of Agriculture Agricultural Research Service; 2013. USDA National Nutrient Database for Standard Reference, release 26. (http://www.ars.usda.gov/Services/ docs.htm?docid=8964).

8. Gahche J, Bailey R, Burt V, et al. Dietary supplement use among U.S. adults has increased since NHANES III (1988-1994). NCHS Data Brief. 2011; 61:1-8. [PubMed: 21592424]

9. Rafferty K, Walters G, Heaney RP. Calcium fortificants: overview and strategies for improving calcium nutriture of the U.S. population. J Food Sci. 2007; 72:R152-R158. [PubMed: 18034744]

10. Prince R, Devine A, Dick I, et al. The effects of calcium supplementation (milk powder or tablets) and exercise on bone density in postmenopausal women. J Bone Miner Res. 1995; 10:1068-1075. [PubMed: 7484282]

11. Straub DA. Calcium supplementation in clinical practice: a review of forms, doses, and indications. Nutr Clin Pract. 2007; 22:286-296. [PubMed: 17507729]

12. Warensjö E, Byberg L, Melhus H, et al. Dietary calcium intake and risk of fracture and osteoporosis: prospective longitudinal cohort study. BMJ. 2011; 342:d1473. [PubMed: 21610048]

13. Shea B, Wells G, Cranney A, et al. Meta-analyses of therapies for postmenopausal osteoporosis. VII. Meta-analysis of calcium supplementation for the prevention of postmenopausal osteoporosis. Endocr Rev. 2002; 23:552-559. [PubMed: 12202470]

14. Jackson RD, LaCroix AZ, Gass M, et al. Calcium plus vitamin D supplementation and the risk of fractures. N Engl J Med. 2006; 354:669-683. [Erratum, N Engl J Med 2006;354:1102.]. [PubMed: 16481635]

15. Lappe JM, Heaney RP. Why randomized controlled trials of calcium and vitamin D sometimes fail. Dermatoendocrinol. 2012; 4:95-100. [PubMed: 22928064]

16. Chung M, Lee J, Terasawa T, Lau J, Trikalinos TA. Vitamin D with or without calcium supplementation for prevention of cancer and fractures: an updated meta-analysis for the U.S. Preventive Services Task Force. Ann Intern Med. 2011; 155:827-838. [PubMed: 22184690]

17. Tang BM, Eslick GD, Nowson C, Smith C, Bensoussan A. Use of calcium or calcium in combination with vitamin D supplementation to prevent fractures and bone loss in people aged 50 years and older: a meta-analysis. Lancet. 2007; 370:657-666. [Erratum, Lancet 2012;380:806.]. [PubMed: 17720017]

18. Reid IR, Bolland MJ, Grey A. Effect of calcium supplementation on hip fractures. Osteoporos Int. 2008; 19:1119-1123. [PubMed: 18286218]

19. Wallace RB, Wactawski-Wende J, O’Sullivan MJ, et al. Urinary tract stone occurrence in the Women's Health Initiative (WHI) randomized clinical trial of calcium and vitamin D supplements. Am J Clin Nutr. 2011; 94:270-277. [PubMed: 21525191]

20. Curhan GC, Willett WC, Speizer FE, Spiegelman D, Stampfer MJ. Comparison of dietary calcium with supplemental calcium and other nutrients as factors affecting the risk for kidney stones in women. Ann Intern Med. 1997; 126:497-504. [PubMed: 9092314]

21. Taylor EN, Curhan GC. Dietary calcium from dairy and nondairy sources, and risk of symptomatic kidney stones. J Urol. 2013 Mar 25. (Epub ahead of print).

22. Bolland MJ, Avenell A, Baron JA, et al. Effect of calcium supplements on risk of myocardial infarction and cardiovascular events: meta-analysis. BMJ. 2010; 341:c3691. [PubMed: 20671013]

23. Hsia J, Heiss G, Ren H, et al. Calcium/vitamin D supplementation and cardiovascular events. Circulation. 2007; 115:846-854. [PubMed: 17309935]

24. LaCroix AZ, Kotchen J, Anderson G, et al. Calcium plus vitamin D supplementation and mortality in postmenopausal women: the Women's Health Initiative calcium-vitamin D randomized controlled trial. J Gerontol A Biol Sci Med Sci. 2009; 64:559-567. [PubMed: 19221190] 
25. Bolland MJ, Grey A, Avenell A, Gamble GD, Reid IR. Calcium supplements with or without vitamin D and risk of cardiovascular events: reanalysis of the Women's Health Initiative limited access dataset and meta-analysis. BMJ. 2011; 342:d2040. [PubMed: 21505219]

26. Bolland MJ, Grey A, Reid IR. Authors' response to editorial. BMJ. 2011; 342:d3520. [PubMed: 21652754]

27. Abrahamsen B, Sahota O. Do calcium plus vitamin D supplements increase cardiovascular risk? BMJ. 2011; 342:d2080. [PubMed: 21505220]

28. Nordin BE, Lewis JR, Daly RM, et al. The calcium scare - what would Austin Bradford Hill have thought? Osteoporos Int. 2011; 22:3073-3077. [PubMed: 21633827]

29. Hennekens $\mathrm{CH}$, Barice EJ. Calcium supplements and risk of myocardial infarction: a hypothesis formulated but not yet adequately tested. Am J Med. 2011; 124:1097-1098. [PubMed: 21798509]

30. Reid IR, Bolland MJ, Grey A. Calcium supplements and risk of myocardial infarction: an hypothesis twice tested. Am J Med. 2012; 125(4):e15. [PubMed: 22444109]

31. Wang L, Manson JE, Song Y, Sesso HD. Systematic review: vitamin D and calcium supplementation in prevention of cardiovascular events. Ann Intern Med. 2010; 152:315-323. [PubMed: 20194238]

32. Lewis JR, Calver J, Zhu K, Flicker L, Prince RL. Calcium supplementation and the risks of atherosclerotic vascular disease in older women: results of a 5-year RCT and a 4.5-year follow-up. J Bone Miner Res. 2011; 26:35-41. [PubMed: 20614474]

33. Li K, Kaaks R, Linseisen J, Rohrmann S. Associations of dietary calcium intake and calcium supplementation with myocardial infarction and stroke risk and overall cardiovascular mortality in the Heidelberg cohort of the European Prospective Investigation into Cancer and Nutrition study (EPIC-Heidelberg). Heart. 2012; 98:920-925. [PubMed: 22626900]

34. Xiao Q, Murphy RA, Houston DK, Harris TB, Chow WH, Park Y. Dietary and supplemental calcium intake and cardiovascular disease mortality: the National Institutes of Health-AARP diet and health study. JAMA Intern Med. 2013; 173:639-646. [PubMed: 23381719]

35. Langsetmo L, Berger C, Kreiger N, et al. Calcium and vitamin D intake and mortality: results from the Canadian Multicentre Osteoporosis Study (CaMos). J Clin Endocrinol Metab. 2013; 98:30103018. [PubMed: 23703722]

36. Cauley J, Wactawski-Wende J, Robbins J, et al. The Women's Health Initiative (WHI) calcium plus vitamin D supplementation trial: health outcomes 5 years after trial completion. J Womens Health (Larchmt). (in press).

37. Kaluza J, Orsini N, Levitan EB, Brzozowska A, Roszkowski W, Wolk A. Dietary calcium and magnesium intake and mortality: a prospective study of men. Am J Epidemiol. 2010; 171:801807. [PubMed: 20172919]

38. Al-Delaimy WK, Rimm E, Willett WC, Stampfer MJ, Hu FB. A prospective study of calcium intake from diet and supplements and risk of ischemic heart disease among men. Am J Clin Nutr. 2003; 77:814-818. [PubMed: 12663277]

39. Bostick RM, Kushi LH, Wu Y, Meyer KA, Sellers TA, Folsom AR. Relation of calcium, vitamin $\mathrm{D}$, dairy food intake to ischemic heart disease mortality among postmenopausal women. Am J Epidemiol. 1999; 149:151-161. [PubMed: 9921960]

40. Michaëlsson K, Melhus H, WarensjøLemming E, Wolk A, Byberg L. Long term calcium intake and rates of all cause and cardiovascular mortality: community based prospective longitudinal cohort study. BMJ. 2013; 346:f228. [PubMed: 23403980]

41. Samelson EJ, Booth SL, Fox CS, et al. Calcium intake is not associated with increased coronary artery calcification: the Framingham Study. Am J Clin Nutr. 2012; 96:1274-1280. [PubMed: 23134889]

42. Manson JE, Allison MA, Carr JJ, et al. Calcium/vitamin D supplementation and coronary artery calcification in the Women's Health Initiative. Menopause. 2010; 17:683-691. [PubMed: 20551849]

43. Rockville, MD: U.S. Preventive Services Task Force; 2012. Vitamin D and calcium supplementation to prevent cancer and osteoporotic fractures in adults: draft recommendation statement. (http://www.uspreventiveservicestaskforce.org/uspstf12/vitamind/draftrecvitd.htm). 
44. Bockman RS, Zapalowski C, Kiel DP, Adler RA. Commentary on calcium supplements and cardiovascular events. J Clin Densitom. 2012; 15:130-134. [PubMed: 22321659]

45. Moyer VA. Vitamin D and calcium supplementation to prevent fractures in adults: U.S. Preventive Services Task Force recommendation statement. Ann Intern Med. 2013; 158:691-696. [PubMed: 23440163] 


\section{key Clinical points}

\section{Calcium Supplements and Fracture Prevention}

- The recommended dietary intake of calcium for women 19 to 50 years of age and men 19 to 70 years of age is $1000 \mathrm{mg}$ per day; women older than age 50 and men older than age 70 require $1200 \mathrm{mg}$ per day. Calcium intake above $2500 \mathrm{mg}$ per day ( $2000 \mathrm{mg}$ per day in persons $>50$ years of age) should be avoided.

- Adequate calcium intake is important for skeletal health at all ages. Inadequate calcium intake in adults is common, particularly in men and women older than 70 years of age, and is associated with increased bone loss and an increased risk of fracture.

- Consumption of calcium-rich foods and beverages is the preferred approach to ensuring adequate calcium intake. There is insufficient evidence to recommend routine calcium supplementation in community-dwelling adults, but supplements should be considered when dietary intake is inadequate.

- Calcium supplements usually have few side effects, although constipation and bloating are common and nephrolithiasis occurs infrequently.

- Recent studies have raised concern about an increased cardiovascular risk with the use of calcium supplements, but the findings are inconsistent and inconclusive. 


\section{Table 1}

Recommended Dietary Intake of Elemental Calcium for Healthy Persons."

\begin{tabular}{|lcc|}
\hline Sex and Age & $\begin{array}{c}\text { RDA } \\
\text { mg/day }\end{array}$ & $\begin{array}{c}\text { Upper Intake Level } \\
\text { mg/day }\end{array}$ \\
\hline Female & & \\
\hline $19-50 \mathrm{yr}^{\dagger}$ & 1000 & 2500 \\
\hline$>50 \mathrm{yr}$ & 1200 & 2000 \\
\hline Male & & \\
\hline $19-50 \mathrm{yr}$ & 1000 & 2500 \\
\hline$>50-70 \mathrm{yr}$ & 1000 & 2000 \\
\hline$>70 \mathrm{yr}$ & 1200 & 2000 \\
\hline
\end{tabular}

The recommended dietary allowance (RDA) is the level of dietary intake that is likely to meet the needs of $97 \%$ of the population. The upper intake level is the level above which the potential for harm increases. Data are from the Institute of Medicine. ${ }^{5}$

${ }^{\dagger}$ This category includes women older than 19 years of age who are pregnant or lactating. 


\section{Table 2}

Well-Absorbed Dietary Sources of Calcium. ${ }^{*}$

\begin{tabular}{|c|c|c|c|}
\hline Type of Food & Serving Size & $\begin{array}{c}\text { Elemental Calcium } \\
\text { per Serving } \\
m g\end{array}$ & $\begin{array}{c}\text { Calories } \\
\text { per Serving } \\
\text { kcal }\end{array}$ \\
\hline \multicolumn{4}{|l|}{ Dairy products } \\
\hline Plain low-fat yogurt & $8.0 \mathrm{oz}$ & 448 & 154 \\
\hline Low-fat yogurt with fruit & $8.0 \mathrm{oz}$ & 384 & 238 \\
\hline Mozzarella, part skim milk & $1.5 \mathrm{oz}$ & 333 & 108 \\
\hline Cheddar cheese & $1.5 \mathrm{oz}$ & 307 & 171 \\
\hline $2 \%$ Low-fat milk & 1 cup & 293 & 122 \\
\hline Low-fat cottage cheese & 1 cup & 206 & 194 \\
\hline \multicolumn{4}{|l|}{ Fruits and vegetables } \\
\hline Calcium-fortified orange juice & $6.0 \mathrm{oz}$ & 261 & 88 \\
\hline Raw kale & 1 cup & 100 & 33 \\
\hline Raw bok choy & 1 cup & 74 & 9 \\
\hline Raw broccoli & 1 cup & 43 & 31 \\
\hline \multicolumn{4}{|l|}{ Canned fish } \\
\hline Sardines & $3.0 \mathrm{oz}$ & 325 & 177 \\
\hline Pink salmon & $3.0 \mathrm{oz}$ & 183 & 110 \\
\hline \multicolumn{4}{|l|}{ Grains } \\
\hline Fortified, ready-to-eat cereals & 1 cup & $100-1333$ & $100-160$ \\
\hline Fortified, cooked oat cereals & 1 cup & 187 & 159 \\
\hline Commercially prepared white or wheat bread & 1 slice & $30-73$ & $69-74$ \\
\hline
\end{tabular}

* These foods contain low levels of oxalic and phytic acid. Data are from the National Nutrient Database for Standard Reference of the U.S. Department of Agriculture. ${ }^{7}$ 


\section{Table 3}

Widely Available Calcium Supplements.

\begin{tabular}{|lccl|}
\hline Formulation & Dose & $\begin{array}{c}\text { Elemental Calcium } \\
\text { Content } \\
\text { percent }\end{array}$ & Comments \\
\hline Calcium carbonate & $\begin{array}{c}\text { One or two 500-mg tablets } \\
\text { taken orally two or three times } \\
\text { daily with meals }\end{array}$ & 40 & $\begin{array}{c}\text { Least expensive and most commonly used supplement; } \\
\text { should be taken with meals, since acidity improves } \\
\text { absorption; can cause constipation }\end{array}$ \\
\hline Calcium citrate & $\begin{array}{c}\text { One or two 950-mg or 1000-mg } \\
\text { tablets taken orally two or three } \\
\text { times daily }\end{array}$ & 21 & $\begin{array}{l}\text { Less dependent on acidity for absorption, so it does not } \\
\text { need to be taken with meals; may be used with agents } \\
\text { for long-term gastric acid suppression }\end{array}$ \\
\hline Calcium gluconate & 500,648, or $972 \mathrm{mg}$ & Rarely used for fracture prevention \\
\hline Calcium lactate & 300 or 325 $\mathrm{mg}$ & Rarely used for fracture prevention \\
\hline $\begin{array}{l}\text { Bone meal, oyster shell, } \\
\text { dolomite }\end{array}$ & Varies & 30 & $\begin{array}{l}\text { Primarily contains calcium carbonate but may contain } \\
\text { detectable lead and should be avoided during pregnancy }\end{array}$ \\
\hline
\end{tabular}

